\title{
Results of engine tests of an experimental gasoline internal combustion engine
}

\author{
Dmitry Maryin, Andrei Glushchenko, Anton Khokhlov, Evgeny Proshkin, and Rail Mustyakimov \\ Ulyanovsk State Agrarian University named after P.A. Stolypin, Ulyanovsk, 432017, Russia
}

\begin{abstract}
To improve the power and fuel and economic performance of a gasoline internal combustion engine, it has been proposed to improve the insulating properties of the piston by forming a heat-insulating coating on the working surfaces of the piston head with a thickness of $25 . .30 \mu \mathrm{m}$ using the microarc oxidation method. Comparative results of engine tests are carried out, which showed that an engine equipped with pistons with a heat-insulating coating on the working surfaces of the head increases power by $5.3 \%$ and reduces hourly fuel consumption by $5.7 \%$ compared to an engine equipped with standard pistons.
\end{abstract}

\section{Introduction}

The current state of development of contemporary engine building is characterized by the fact that designers' pay special attention to a forced flow of gasdynamic, thermal, power and strength modes of the engine performance. In its turn, these modes are accompanied by a further increase in the thermal density of the main components that form the combustion chamber, which is caused by a change in the flow of the working process and engine performance. One of the most loaded parts of the cylinder-piston group (CPG) is the piston, which is exposed to high mechanical and thermal loads [1]. The piston overheating leads to premature wear of the rubbing surfaces, the sticking of piston rings and their breakdowns, jamming of the pistons, burnout of the piston head, etc.

It has been found that in the engine building practice various methods are used to reduce the thermal stress of ICE pistons.

The main disadvantages of these methods are changes in the geometrical parameters, the complexity of their design and engine cooling system, a weight increase, and as a result, reduced durability and reliability, etc.

Modern technology can provide protection for engine parts exposed to thermal stress, especially pistons, through the use of structural coatings or special insulating materials. The main idea of such a coating is to reflect heat energy back into the combustion chamber, which should prevent the piston overheating.

Equipping a diesel engine with pistons with a heat insulating ceramic coating with a thickness of $0.2-0.9 \mathrm{~mm}$ makes it possible to reduce effective fuel consumption by 6-8 $\mathrm{g} /(\mathrm{kW} \cdot \mathrm{h})$, by reducing heat loss and more complete combustion of fuel, compared to an engine, equipped with standard pistons [2].
Experimental studies conducted on a $1 \mathrm{ChN} 18$ / 20 diesel engine, equipped with aluminum pistons coated with alumina $(0.25-0.3) \cdot 10^{-3} \mathrm{~m}$ thick, show that the effective fuel consumption in the nominal mode decreases by $2.7 \mathrm{~g} /(\mathrm{kW} \cdot \mathrm{h})$, and on a diesel engine $2 \mathrm{ChN} 21 / 21$ at $\mathrm{n}=1200 \mathrm{~min}^{-1}$ and $\varphi$ top $=36-38^{\circ}$, the effective fuel consumption decreases by $5.44 \mathrm{~g} /(\mathrm{kW} \cdot \mathrm{h})$ [3].

The use of heat insulating coatings of aluminum oxide with a thickness of $(0.2-0.25) \cdot 10^{-3} \mathrm{~m}$ on the pistons of the ship's low-speed diesel engine 1Ch 24/36 with the volumetric mixture formation, caused a decrease in the effective fuel consumption at loads less than $45 \%$ of the effective engine power by $2.5-13 \mathrm{~g} /(\mathrm{kW} \cdot \mathrm{h})$ [3].

It is known that for thermal protection of the working surfaces of the piston top and cylinder head of a twostroke internal combustion engine (ICE), pistons and cylinder heads with a thermal insulating oxide ceramic coating $0.06 \mathrm{~mm}$ thick were used. This made it possible to reduce heat removal from the working surfaces of parts, to reduce the specific fuel consumption by $3.2 \%$ and increase the maximum engine power by $6 \%$ [4].

As a result of testing the D-240L diesel engine, it has been established that an engine equipped with pistons with a heat-insulating corundum coating can increase power by $8.6 \%$ and reduce specific fuel consumption by $6.6 \%$ compared to an engine equipped with standard pistons.

As a result of bench tests of the D65NT1 diesel engine equipped with pistons with a corundum layer and a Teflon coating of friction surfaces, a decrease in fuel consumption by $5.1 \%$ was established, an increase in developed power from $44.72 \mathrm{~kW}$ to $46.7 \mathrm{~kW}$, i.e. by $4.4 \%$. This was due to a decrease in total thermal and mechanical losses due to internal friction. There was a decrease in the smoke opacity of the exhaust gases from 46 to $30 \%$ [5].

* Corresponding author: denmol@yandex.ru 
Thus, heat insulating coatings formed on the working surfaces of the piston, significantly improve the performance of the diesel. "Stiffness" of the combustion process and the maximum pressure during combustion go down, which leads to a decrease in noise, vibration of the diesel engine and toxicity of exhaust gases. Increasing the rate of combustion in the main phase of combustion increases the completeness of combustion and provides operation that is more economical.

However, the use of heat insulating coatings did not find further application to improve the insulating properties of the piston, power, fuel and economic performance of the engine, because in the process of operation, these coatings have two significant drawbacks: low adhesive strength on piston alloys and low heat resistance.

\section{Materials and research methods}

In recent years, one of the effective methods of forming heat-insulating coatings is microarc oxidation (MAO) [6], which makes it possible to create surface coatings that have completely new heat-conducting properties than the main material of the part, while the geometric parameters and the weight of the workpiece do not change.

On the basis of the results obtained, the experimental sets of pistons with a heat insulating coating on the working surfaces of piston heads were manufactured under the following microarc oxidation modes: the concentration of orthophosphoric acid in the water solution is $180 \mathrm{~g} / \mathrm{l}$; density of electric current $-4 \mathrm{~A} / \mathrm{dm}^{2}$, voltage supplied to the piston head $-250 \mathrm{~V}$, electrolyte temperature $-25{ }^{\circ} \mathrm{C}$, oxidation time -60 minutes (figures 1) [7].

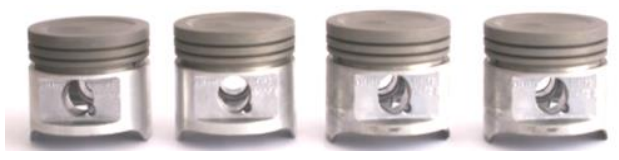

Fig. 1. General view of a set of pistons with a heat insulating coating of the working surfaces of the heads.

The analysis of the thickness, porosity, structure and element composition of the heat-insulating coating of a metallographic sample of an experimental piston fragment was carried out with the use of scanning electron microscopy with X-ray microanalysis. A complex unit consisting of a Zeiss SUPRA 55VP highresolution field emission scanning microscope complete with an Inca Energy 350 energy dispersive spectrometer, an Inca Wave 500 wave spectrometer, and the HKL EBSD Premium System for reflected electron diffraction were used in the studies.

The metallographic sample was a fragment of an experimental piston made of aluminum alloy with a thickness of about $2 \mathrm{~mm}$ (figures 2). The studied sample was placed in the vacuum chamber of the microscope. The element analysis of the heat insulation coating was performed along four routes. All routes had a length of $100 \mu \mathrm{m}$ from the outer surface of the piston and consisted of 10 levels with a step of $10 \mu \mathrm{m}$ (the first level is closest to the surface). To obtain a picture of topographic contrast, the sample was thoroughly washed with a solvent and degreased using an ultrasonic cleaning method in an ultrasonic bath UZV-15M in order to avoid fouling with hydrocarbon.

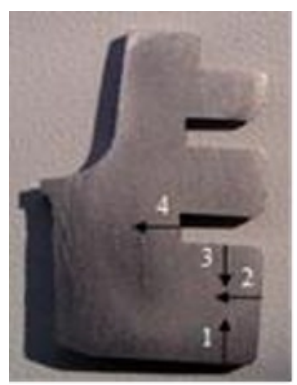

a)

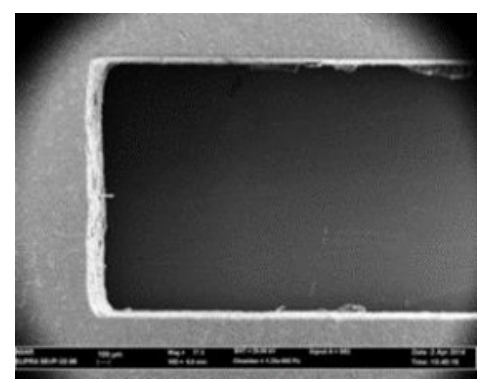

b)
Fig. 2. The metallographic sample of a piston fragment: a) a macro photograph of the sample, indicating the routes of element analysis; b) an image of the surface layers of the sample

As a result of the conducted study of the structure and element composition of the experimental piston fragment, it has been found that the heat insulating coating has good adhesion with the main material of the aluminum alloy. There is clear relief and is heterogeneous in its composition, there are no cracks and fractures in the contact area "the main material - heat insulation coating". The interpenetration of the oxidized layer into the base material is clearly observed. The thickness of the oxidized layer is $24 . . .31$ microns, the porosity is $10 \ldots 11 \%$ [8]. route 1

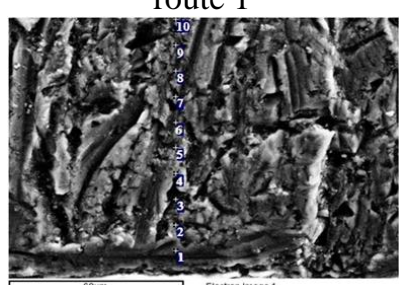

route 3

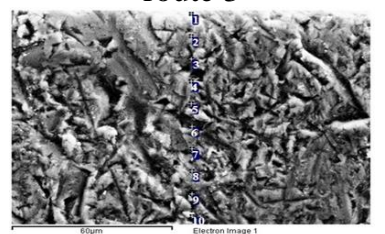

route 2

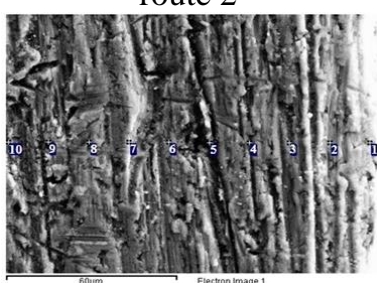

route 4

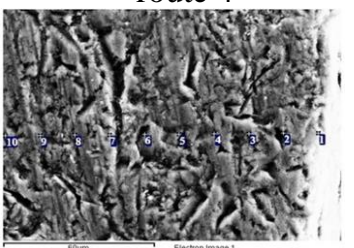

Fig. 3. The structure of the surface layer of oxidized working surfaces of the piston heads

The oxidized layer formed on the sample fragment surface of the experimental piston is metal oxide. According to the results of the element composition in atomic concentrations, normalized to $100 \%$, taking account of all the registered elements, it was found that the main elements of the material studied are silicon, aluminum and oxygen. The oxygen content in the oxidized layer along route 1 increased by $18.9 \%$, along route 2 - by $10.3 \%$, along route 3 and 4 , respectively, by 
15 and $12.7 \%$, compared to a standard piston, which is indicative of the formation of corundum (Al2O3) in the oxidized layer (figures 3 ).

For a comparative assessment of the power, fuel, economic and environmental performance of engines, in standard (typical pistons) and experimental (pistons with insulating coating) configurations, engine tests were performed according to GOST 14846-81 at the MEZVsetin 926-4/V brake test bench with standard instrumentation (figures 4).

The performance indexes of the engine in engine tests were determined in terms of speed and load characteristics. Indicators of the load characteristics of the engine were determined at a crankshaft rotational speed of 2200 min-1, since this frequency corresponds to the maximum torque according to the external speed characteristic of the UMZ-421 engine and is recommended by the manufacturer when taking the measuring points' readings.

The speed and load characteristics of the engine were taken after running in for 35 hours at load - speed and temperature conditions.

All the systems and mechanisms of the engine were pre-checked and adjusted according to the instruction manual of the UAZ family of vehicles.

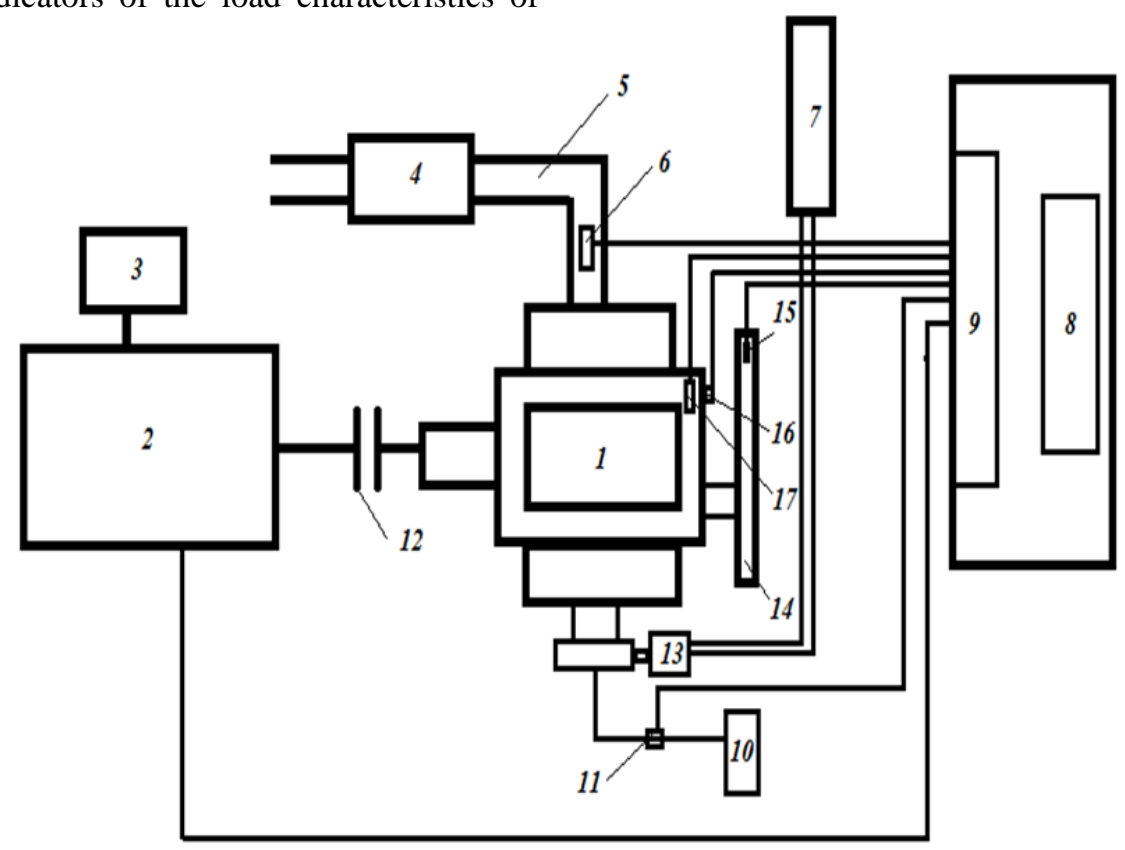

Fig. 4. Structural diagram of the brake stand: 1 - internal combustion engine; 2 - engine test bench; 3 - balance dynamometer; 4 silencer; 5 - exhaust system; 6 - gas analyzer; 7 - receiver for air; 8 - control panel; 9 - instrument panel from sensors on the engine; 10 - fuel tank; 11- device for measuring fuel consumption; 12 - engine coupling with a stand; 13 - air filter; 14 - water cooling system; 15 - temperature gauge of the engine cooling system; 16 - engine oil pressure gauge; 17 - electronic tachometer

\section{Research results and their discussion}

As a result of conducted engine tests, high-speed (fig. 5) and load (fig. 6) characteristics of engines in standard and experimental configurations were built.

The analysis of the speed characteristics of the engine shows that there is an increase in the effective power of the engine $\left(N_{e}\right)$ equipped with heat-insulated coating pistons, in the entire range of crankshaft rotational speeds.
The maximum effective power of an engine (at a crankshaft rotation speed of $4200 \mathrm{~min}^{-1}$ ) equipped with a piston with a heat insulating coating (figures 5) was $77.5 \mathrm{~kW}$, which is $5.3 \%$ more compared to the power of an engine equipped with standard pistons $(73.6 \mathrm{~kW})$. The specific effective fuel consumption $\left(g_{e}\right)$ at maximum power $\left(\mathrm{n}=2200 \mathrm{~min}^{-1}\right)$ of an engine equipped with a piston with a heat insulating coating decreased by $9.4 \%$ and amounted to $272.9 \mathrm{~g} / \mathrm{kW}$, while for an engine equipped with standard pistons, it is equal to $301.2 \mathrm{~g} / \mathrm{kW}$ (figures 5). The hourly fuel consumption $\left(G_{T}\right)$ was $23.1 \mathrm{~kg} / \mathrm{h}$ and $24.5 \mathrm{~kg} / \mathrm{h}$, respectively (figures 5 ). 


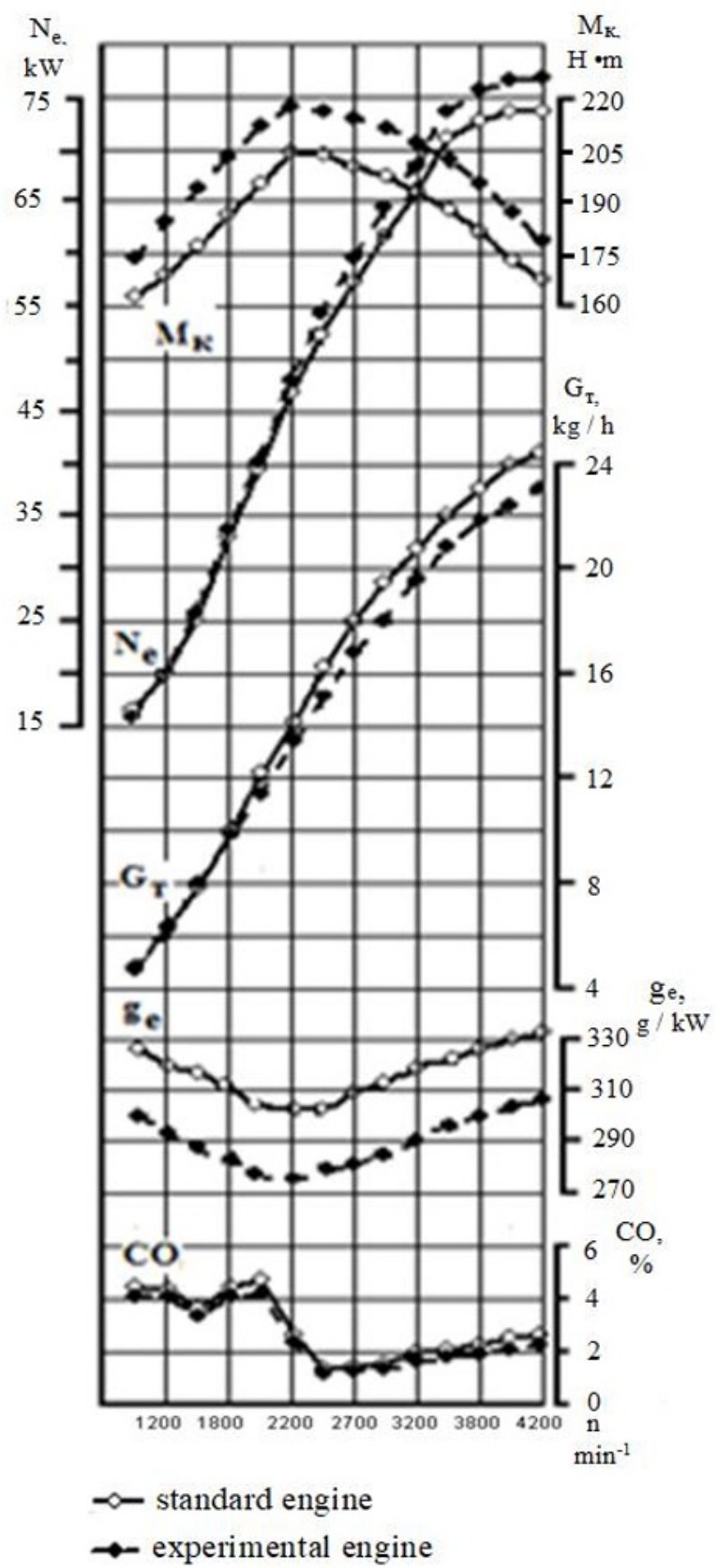

Fig. 5. The speed characteristic of a standard engine and an experimental engine

Maximum torque (MT) at a rotational speed of $2200 \mathrm{~min}^{-1}$ was $217.4 \mathrm{H} \cdot \mathrm{m}$ for an engine equipped with thermally insulated pistons and $204.1 \mathrm{H} \cdot \mathrm{m}$ for an engine equipped with standard pistons (figures 5).

The analysis of the obtained load characteristics shows (figures 6) that in the maximum load mode, the hourly fuel consumption of an experimental engine with a rated power of $55 \mathrm{~kW}$ was $15.3 \mathrm{~kg} / \mathrm{h}$, whereas for a standard engine it was $16.1 \mathrm{~kg} / \mathrm{h}$.

Measurements of the carbon oxide content $(\mathrm{CO})$ and carbon hydride $(\mathrm{CH})$ in the exhaust gases showed that in the engine equipped with heat-insulated pistons compared to the engine equipped with standard pistons, the $\mathrm{CO}$ content decreased by an average of $13 \%$ and $\mathrm{CH}$ by $9.3 \%$ (figures 6 ).

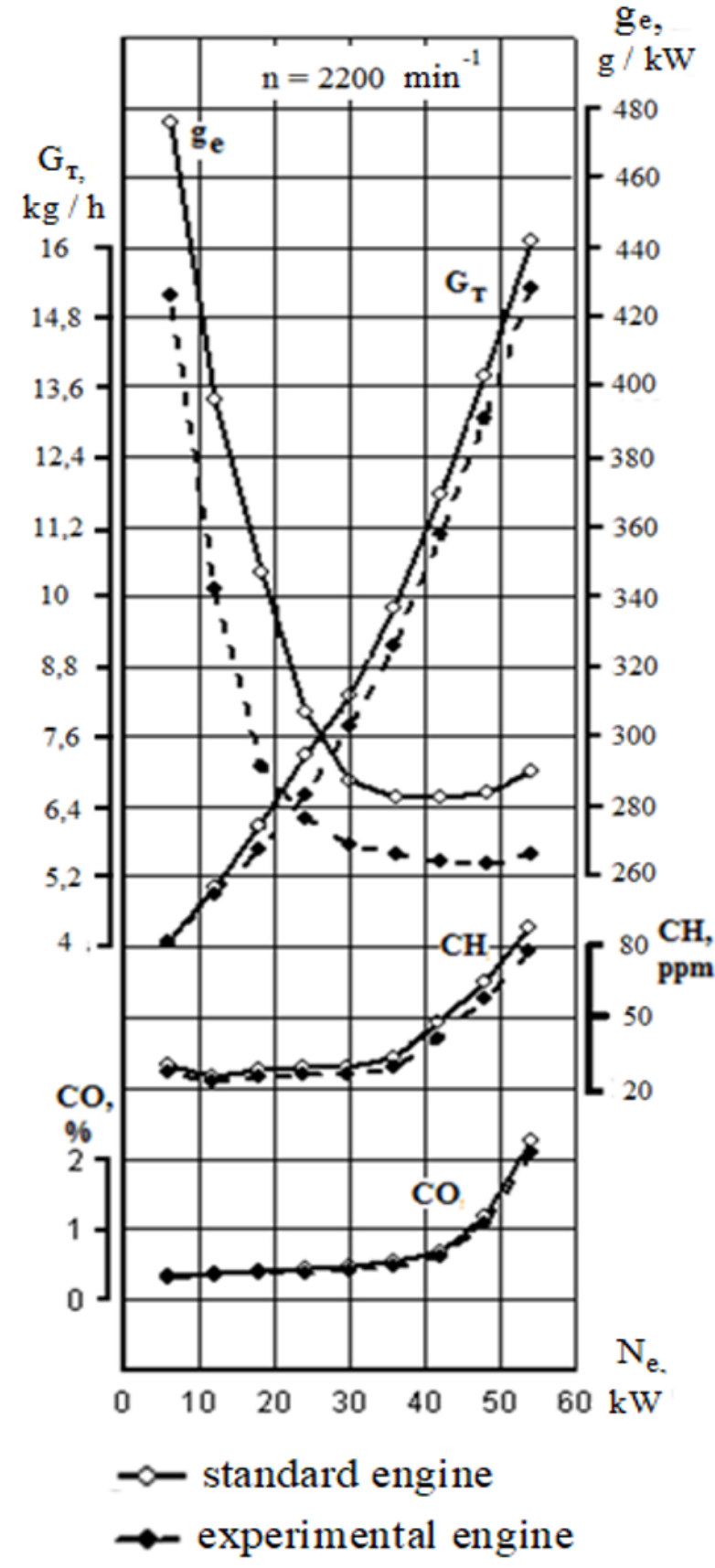

Fig. 6. Load characteristics of a standard engine and an experimental engine

\section{Conclusion}

According to the results of the tests, the following outcome has been found: the use of pistons with a heat insulating coating on the working surfaces of the heads in the UMZ-421 engine allows increasing its effective power by $5.3 \%$, maximum torque by $6.5 \%$, reducing the hour and specific effective fuel consumption by 5.7 and $9.4 \%$ respectively, the content in the exhaust gases of carbon monoxide by $13 \%$ and hydrocarbons by $9.3 \%$, compared with an engine equipped with standard pistons. 


\section{References}

1. D.A. Sibrikov, A thermal stress decrease of piston groups of ship diesel engines, $\mathrm{PhD}$ dissertation (Novosibirsk, 2004)

2. A.K. Kostin, B.P. Pugachyov, Yu.Yu. Kochinev, The performance of diesel engines under operating conditions (Mashinostroenie, Leningrad, 1989)

3. M.D. Nikitin, A.Ya. Kulik, N.I. Zakharov, Heatinsulating and wear-resistant coatings for diesel engine parts (Mashinostroenie, Leningrad, 1977)

4. N.M. Chigirinova, V.V. Chigirinov, V.E. Chigirinov, Oxide ceramic coatings - effective thermal protection of working surfaces of $C P G$ parts, Automot. Industry, 6, 30-34 (2004)

5. V.V. Shpakovsky, O.Yu. Linkov, The effectiveness analysis of the use of pistons with a corundum layer to reduce fuel consumption, Aerospace Engineer. and Technol., 10(57), 140-144 (2008)

6. A.L. Khokhlov, D.A. Ukhanov, A.A. Glushchenko, D.M. Maryin, V.A. Stepanov, The influence of microarc oxidation modes on the formation of an oxidized layer, Bull. of the Ulyanovsk State Agricult. Acad., 3(23), 128-131 (2013)

7. A.L. Khokhlov, D.M. Marin, A.A. Glushchenko, D.A. Ukhanov, Results of theoretical and experimental studies of the thermal stress of an internal combustion engine piston with an oxidized piston top, Niva Povolzhya, 2(27), 100-106 (2013)

8. D.M. Maryin, A.L. Khokhlov, A.A. Glushchenko, Structure and element composition of the oxidized layer on the top and grooves of the engine piston, in Proc. of the X Int. Sci. Conf. "News of Advanced Science-2014," 56-60 (Byal Grad-BG Ltd., Sofia, 2014) 